\title{
HACIENDA LOCAL, SERVICIOS PÚBLICOS URBANOS E INDUSTRIALIZACIÓN. EL ALUMBRADO PÚBLICO DE LA CIUDAD DE ALICANTE: DEL ANTIGUO RÉGIMEN AL LIBERALISMO (1815-1874)
}

\section{SALVADOR SALORT VIVES}

Departamento de Análisis Económico Aplicado. Universitat d'Alacant

\section{RESUMEN}

Este artículo pone en relación la capacidad financiera de la Hacienda de la ciudad de Alicante para satisfacer la provisión del alumbrado público, entre 1815 y 1874, y sus repercusiones sobre el proceso industrializador. El trabajo recoge las normas reguladoras de este servicio, sus modalidades de gestión y el impacto tecnológico de la industrialización. Concluye, con evidencias empíricas, que el insuficiente nivel financiero de este demandante institucional, que derivó en un elevado grado de endeudamiento, tuvo un notable grado de responsabilidad en la descapitalización de los individuos y empresas oferentes de este servicio, sobre todo de las fábricas productoras de gas y, por tanto, pudo influir en el retraso del proceso industrializador.

\section{ABSTRACT}

This article connects the financial capacity of the public finance of the city of Alicante in order to provide street lighteing, between 1815 and 1874, with its repercussions on the process of industrialization. The work deals with the rules that regulate this service, forms of management and the technological impact of the industrialization. It comes to the conclusion that the insufficient financial level of this institutional consumer, caused a high debt. It was responsible, to a large extent, for the loss of capital of the individuals and the enterprises offering that service, especially the gas producing factories and therefore, could have an influence in the delay of the industrialization process. 


\section{INTRODUCCIÓN}

Las infraestructuras y servicios públicos urbanos municipales, elementos básicos de la economía de las ciudades, obedecen a las necesidades demandadas por la concentración de la población en los núcleos urbanos, para cuya satisfacción se han producido diversos sistemas técnicos y distintas y especiales formas de gestión, pública y privada. En la evolución histórica de la provisión de los servicios públicos locales desde el siglo XviI, el proceso industrializador significó una solución de continuidad, tanto desde el punto de vista tecnológico, como desde la óptica de la asignación de su iniciativa y control ${ }^{1}$. Por otra parte, desde el punto de vista de la demanda, la industrialización se vio afectada por la voluntad política y las posibilidades financieras de los ayuntamientos como consumidores institucionales. La subordinación de las Haciendas locales a los intereses de la Hacienda central, tanto desde el punto de vista de los ingresos como desde la vertiente de los gastos, no fue ajena ni a la disponibilidad de recursos municipales ni a su libre asignación.

En este contexto se enmarca el presente trabajo sobre alumbrado públi$\mathrm{Co}^{2}$. Su atención se centra en su insistente demanda social; en las normas reguladoras de esta provisión; en las modalidades de gestión de este ramo; y en la insuficiente capacidad financiera de esta Hacienda local para su satisfacción, hecho que derivaba en un creciente grado de endeudamiento, que repercutía perversamente sobre los individuos y empresas concesionarias. Con ello pretendo contribuir a conocer el difícil tránsito de una ciudad sin apenas servicios públicos a otra en la que se iniciaría el «municipio de bienestar»; y también a desentrañar el grado de responsabilidad que la demanda pública local, mediatizada en sus bases financieras por la Hacienda central, tuvo en la aceleración o retraso de la industrialización, sobre todo desde el establecimiento del sistema por gas. En este último sentido, se desea aportar una experiencia histórica concreta a los estudios ya realizados desde la perspectiva de la producción gasista, de su financiación, fundamentalmente extranjera, del impacto de los cambios tecno-

Diversos autores han tratado sobre estas cuestiones. Así, Núñez (1996b) ha señalado el papel de las ciudades como centros de innovación y difusión tecnológica. Antolín (1991) ha puesto de relieve las diversas formas en la provisión de los servicios urbanos en la historia, y Costa (1981) ha sostenido el cambio cuantitativo y cualitativo que las empresas de servicios públicos urbanos tuvieron en el desarrollo del capitalismo.

${ }^{2}$ La provisión de alumbrado a otros consumidores, variable importante para el desarrollo de las industrias suministradoras, queda fuera de los objetivos de esta aportación. 
lógicos y del papel que su actividad económica generada ha tenido en el proceso de industrialización y asentamiento del capitalismo en España ${ }^{3}$.

\section{EL MARCO NORMATIVO: CUENTAS, PRESUPUESTOS Y REGULACIÓN LEGAL DEL ALUMBRADO}

La regulación del servicio de alumbrado público de esta ciudad desde la segunda mitad del siglo XvIII hasta el período finisecular de la centuria pasada, estuvo vinculada al cambio de las normas del Antiguo Régimen por las del Liberalismo. Hasta la Revolución burguesa, exceptuados los breves y efímeros períodos liberales de las Cortes de Cádiz y del Trienio Constitucional, ni existieron los Presupuestos municipales ni en las Tablas absolutistas de gastos locales, establecidos en 1760, hubo una partida específica para consignar los gastos de alumbrado. Significativamente, los registros contables de desembolsos por este concepto se englobaban en una especie de cajón de sastre denominado «Gastos ordinarios y extraordinarios alterables», que hablan bien a las claras de su carácter secundario y de la escasa importancia que se le concedía. Además, estos gastos se anotaban junto a otros concernientes a celebraciones regias, religiosas y «regocijos» varios ${ }^{4}$.

El segundo modelo en la estructura del gasto municipal sufrió los sobresaltos consecuentes a la intermitencia de los períodos liberales de 1808-1812

${ }^{3}$ Sobre las implicaciones financieras en la provisión de este servicio público, véase Tortella (1982 y 1994); acerca de las inversiones francesas en los servicios públicos municipales, Broder (1981); en relación a las inversiones extranjeras vinculadas a la consolidación de la estructura económica de los países industrializados y la revolución tecnológica, Costa (1981); en cuanto a los antecedentes de la industria del gas en Europa y su aplicación ai alumbrado, su introducción y expansión en España por la iniciativa privada foránea, su gestión y la evolución de las empresas concesionarias, véase Sudrià (1983) y Antolín (1991). Esta última investigadora, además, ha tratado sobre las condiciones generales de los contratos entre los propietarios y los Ayuntamientos, para su suministro. Por su parte, Nadal (1992) ha puesto de manifiesto la relación entre el desarrollo de la industria gasista en España y el nivel de consumo.

4 La normativa absolutista en relación a los gastos locales fue fijada, fundamentalmente, en el Decreto de 30 de julio de 1760 y la aneja Instrucción y se mantendría, prácticamente inalterada, hasta la década de los años cuarenta del siglo XIX. La partida de gastos de alumbrado estaba incluida, junto a una gran diversidad de otros conceptos, en los «gastos alterables», lo que da idea de la escasa racionalidad y la suma discrecionalidad en la asignación de recursos del Ayuntamiento absolutista. Estas circunstancias obligan al investigador a tener que rastrear los datos económicos correspondientes a determinadas partidas del gasto, como la del alumbrado, en varios apartados de la clasificación orgánica que ofrece la documentación. Véase Salort (1997). 
y 1820-1823, iniciando una andadura más serena a partir de 1836-1839, para afianzarse desde 1846. En virtud de las atribuciones y competencias que la Constitución de 1812 concedía a los Ayuntamientos y a impulsos de las nuevas disposiciones liberales, las Corporaciones locales iniciaron un proceso de asunción de nuevos servicios, o de normalización de los ya existentes, consignando las cargas debidamente en los Presupuestos municipales, correspondiendo así a las necesidades que demandaba la sociedad. Éste fue el caso de la partida del Alumbrado público, que quedó comprendida en el capítulo de Policía Urbana y Rural ${ }^{5}$. Simultáneamente, la regulación específica del alumbrado público se fue estableciendo en los años finales de la transición desde el Régimen absoluto al Liberalismo. Así, la Real Orden de 16 de septiembre de 1834 disponía el «establecimiento de serenos y alumbrado en las capitales de provincia donde no lo hubiere y de su reforma en aquellos en que aunque lo haya, sea susceptible de mejorarse». A partir de la segunda mitad del siglo XIX, una vez instituido el Régimen liberal, la normativa acerca de esta provisión pública quedaría fijada por el Real Decreto de 27 de febrero de 1852 y las posteriores Instrucciones, de 19 de marzo y de 15 de noviembre del mismo año, sobre contratación de obras y servicios públicos municipales y provinciales «de alguna importancia». Después de la aplicación del gas al alumbrado, el Real Decreto del Ministerio de Fomento de 28 de marzo de 1860 dispuso la regulación gubernamental de los contadores de gas «para asegurar la bondad del sistema a que pertenecen los aparatos (...) [fijar] la exactitud de los instrumentos de comprobación (...) [y conseguir] el acierto en esta operación». Por otra parte, la Ley de 29 de junio de 1864 obligaba a los Ayuntamientos a instalar y mantener el alumbrado público en las nuevas calles abiertas en los Planes de Ensanche. Finalmente, por el artículo 67 de la Ley de Ayuntamientos de 1870 se confiaba a la exclusiva competencia municipal el establecimiento, gestión y dirección de este servicio y por el artículo 72 de la Ley Municipal de 1877 se prohibió a las Corporaciones locales la concesión del monopolio de este ramo.

${ }^{5}$ Desde 18401845 se estabilizó la estructura del gasto del Ayuntamiento burgués y la partida del alumbrado público se integró en los «gastos obligatorios». Pero, al igual que ocurría en el Antiguo Régimen, el investigador ha de desagregar esta partida del capítulo total. En 1846 se introdujeron ligeras modificaciones en el cuadro de gastos con respecto a 1845, quedando prácticamente fijada la clasificación orgánica hasta 1923. Véase Salort (1997). 


\section{DEL AYUNTAMIENTO ABSOLUTISTA AL AYUNTAMIENTO LIBERAL: EL ALUMBRADO POR EL CANDIL DE ACEITE (1815-1858)}

Los orígenes contemporáneos de una cierta preocupación por el alumbrado público de esta ciudad hay que situarlos en la última década del siglo XviI, en los epígonos del aliento reformista ilustrado. Por la Real Cédula de 13 de agosto de 1790 se concedió a esta Hacienda local el arbitrio de cuatro maravedíes por cada libra de nieve que se consumiera en el casco urbano, con el propósito de financiar la instalación de 460 farolas de aceite, para una población que contaba con unos 20.000 habitantes. El monto total ascendió a 37.000 reales de vellón, que adelantó el Corregidor. Las condiciones de esta autorización fijaban que una vez reintegrados los gastos del establecimiento completo del alumbrado, el impuesto se reduciría a sólo dos maravedíes por libra de nieve para el mantenimiento del servicio. Siguiendo su tradición, el Ayuntamiento arrendó conjuntamente la recaudación del arbitrio y la gestión del servicio. Abonados los 37.000 reales citados a los pocos años, se suspendió la recaudación de los dos maravedíes destinados a la instalación, subsistiendo sólo el impuesto de los otros dos maravedíes. Pero a partir de 1815, el Ayuntamiento pidió la reanudación de la percepción de cuatro maravedíes ante la insuficiencia de recursos, lo que había dejado el servicio del alumbrado en la «mayor decadencia». La penuria radicaba en la ampliación del casco urbano desde 1808 y el aumento de los faroles y, sobre todo, en la subida del precio de los artículos de primera necesidad, lo que había retraído el consumo de la nieve, y había disparado los costes del aceite, hechos que habían disuadido a los arrendadores del servicio del alumbrado a intervenir en las subastas ${ }^{6}$. Esta petición no tuvo respuesta y el Ayuntamiento, por su cuenta y riesgo, restableció el gravamen de los cuatro maravedíes. Pero la alegría duró poco puesto que desde 1817, con el Derecho de Puertas de Garay, la Real Hacienda recaudó todos los arbitrios municipales y, entre ellos, los dos maravedíes por libra de nieve legalmente autorizados, cuyo

' La petición al Rey, de 15 de octubre de 1815, en AMA. Copiador de correspondencia. 1814-1816. Armario 12, libro 76. La ampliación del casco urbano de la ciudad desde 1808 se realizó con motivo de las nuevas fortificaciones que se hicieron para resistir al Ejército francés, con lo que quedaron incluidos los arrabales dentro de la línea de la nueva muralla, además de otros ensanches verificados en la costa. Véase Ramos (1984). 
producto debía de entregar al Ayuntamiento. La protesta municipal no tardó en llegar, repitiendo los mismos argumentos ya conocidos ${ }^{7}$.

Hasta 1830, y exceptuados los dos primeros años del Trienio Constitucional, durante los cuales se medio abolieron los arbitrios sobre el consumo y, por tanto, el de la nieve, el Ayuntamiento mantuvo ilegalmente el arbitrio de los cuatro maravedíes por libra de nieve, a pesar del restablecimiento del Derecho de Puertas. Pero en el año citado, el arrendamiento gubernamental de la recaudación de todos los gravámenes, arbitrios incluidos, a la Empresa de Puertas que, lógicamente, se quedaba con los dos maravedíes legalmente establecidos, desató de nuevo la indignación de la Corporación municipal. La denuncia del Ayuntamiento ante el Corregidor y el Intendente, sin embargo, se volvió contra la institución municipal; ya que la Intendencia y la Contaduría de Propios abrieron una investigación acerca del origen, legalidad y cuentas de este arbitrio, descubriéndose el abuso en el que largamente había incurrido el Ayuntamiento, percibiendo, directamente o por arriendo, los cuatro maravedíes, y la carencia de contabilidad respecto a los ingresos y gastos por el alumbrado, desde finales del siglo XVII ${ }^{8}$. El Ayuntamiento se defendía argumentando que no tenía por qué dar cuentas a la Contaduría y que había sido imprescindible la recaudación de los cuatro maravedíes, ante la gran necesidad e insuficiencia de este servicio. En su opinión, si al arrendador del alumbrado se le privaba de los dos maravedíes, sólo se podrían encender 135 faroles de los 270 existentes, que ya resultaban insuficientes. Advertía la Corporación que si no podía disponer del gravamen completo, suministraría el servicio sólo parcialmente, cosa que hizo, o lo suprimiría totalmente, renunciando al arbitrio. La restricción del servicio provocó la protesta de los vecinos y del Gobernador Militar, por la inseguridad creada?.

${ }^{7}$ El Derecho de Puertas fue establecido en esta ciudad a petición de la propia Corporación local y el influyente lobby del Consulado de Comercio. La oposición del Ayuntamiento a la recaudación de este arbitrio por parte de la Real Hacienda se enmarca en el antagonismo a la percepción de todos los impuestos municipales por parte de ésta. Véase Salort (1997). La protesta del Comisionado del alumbrado en AMA. Alumbrado. 1817. Legajo 1, núm. 5.

${ }^{8}$ Las conclusiones del Informe del Contador Principal al Intendente de Valencia, de 4 de septiembre de 1830, en ADPA. Cuentas municipales de 1830-1831. Legajo 2.034.

${ }^{9}$ En su oficio de 20 de noviembre de 1831 al Intendente, el Ayuntamiento insistía en la inevitabilidad de la recaudación de los cuatro maravedíes, habida cuenta de la contracción de los ingresos a causa de «la subida enorme del precio del aceite que se notó por efecto de las mismas vicisitudes (Guerra de la Independencia) [que] pusieron en tan mal estado el alumbrado y sus fondos (...). Así ha corrido hasta el día, sin reconocerse términos hábiles para hacer novedad, porque la disminución del vecindario y sus cortos 
En 1832, la Dirección General de Propios y Arbitrios del Reino, a la que había consultado la Intendencia de Valencia, decidió autorizar sólo dos maravedíes, que seguirían siendo recaudados por la Empresa de Puertas y transferidos al Ayuntamiento; suplir de los fondos generales el déficit existente y los pagos corrientes por este ramo, mientras la Corporación propusiera otros arbitrios; y exigir que se consignaran en las cuentas los ingresos y gastos por alumbrado, así como la presentación de las cuentas anteriores ${ }^{10}$. Hasta 1845 , con independencia de que a partir de 1837 se iniciaran los Presupuestos y se consignara ya específicamente una partida para los gastos de alumbrado, la tónica general de este servicio público sería la insuficiencia financiera y, por tanto, la limitación en su provisión a la ciudadanía, cosa que los ayuntamientos progresistas a partir de 1836 lamentarían. La intervención de los arbitrios municipales por parte de la Hacienda central o de la Empresa de Puertas y la práctica imposibilidad de imponer nuevos arbitrios sobre el consumo, que no chocasen con los establecidos por el Gobierno ni conculcaran la libertad de la economía de mercado, explican el agobio presupuestario municipal y, consecuentemente, la limitación de este servicio local, que se mantuvo con lo que le transferían Hacienda o la Empresa y con lo que el Ayuntamiento podía rebañar de otros ingresos generales ${ }^{11}$. De todos modos, entre 1830 y 1840 se amplió el servicio de alumbrado y se introdujeron innovaciones tecnológicas, aunque con grandes dificultades y de forma insuficiente. Así, desde 1835 , en aplicación de la Real Orden de 1834, se estudió la posibilidad de instalar faroles de reverbero, que permitían una mejor iluminación. Aunque el proceso no se culminó totalmente por falta de recursos, en 1844 la ciudad contaba con 87 faroles de reverbero, similares a los instalados en Aranjuez, y 136 pequeños, para iluminar a una población de unos 18.000 habitantes ${ }^{12}$.

En cuanto a la gestión de este servicio y a la recaudación de su correspondiente arbitrio entre 1790 y 1836 , el Ayuntamiento recurrió, en general

\footnotetext{
haberes, al paso que han hecho bajar el consumo, el producto del arbitrio ha venido también a menos». AMA. Copiador de correspondencia. 1830-1831. Armario 12. Libro 76.

${ }^{13}$ La resolución de la Dirección General de Propios y Arbitrios del Reino, de 29 de febrero de 1832, en ADPA. Cuentas municipales de 1832. Legajo 2.034.

1 Para las razones de la insuficiencia financiera municipal de esta ciudad entre 1800 y 1845 , véase Salort (1997).

${ }_{12}$ Los diversos proyectos no realizados hasta 1844 por falta de financiación debida, entre otras cosas, a las transferencias a la Hacienda central, en AMA. Alumbrado. 1835-1844. Legajo 1, núms. 13, 14, 17 y 19. Para las contribuciones municipales a la Real Hacienda y demás detracciones practicadas a esta Hacienda local, véase Salort (1997).
} 


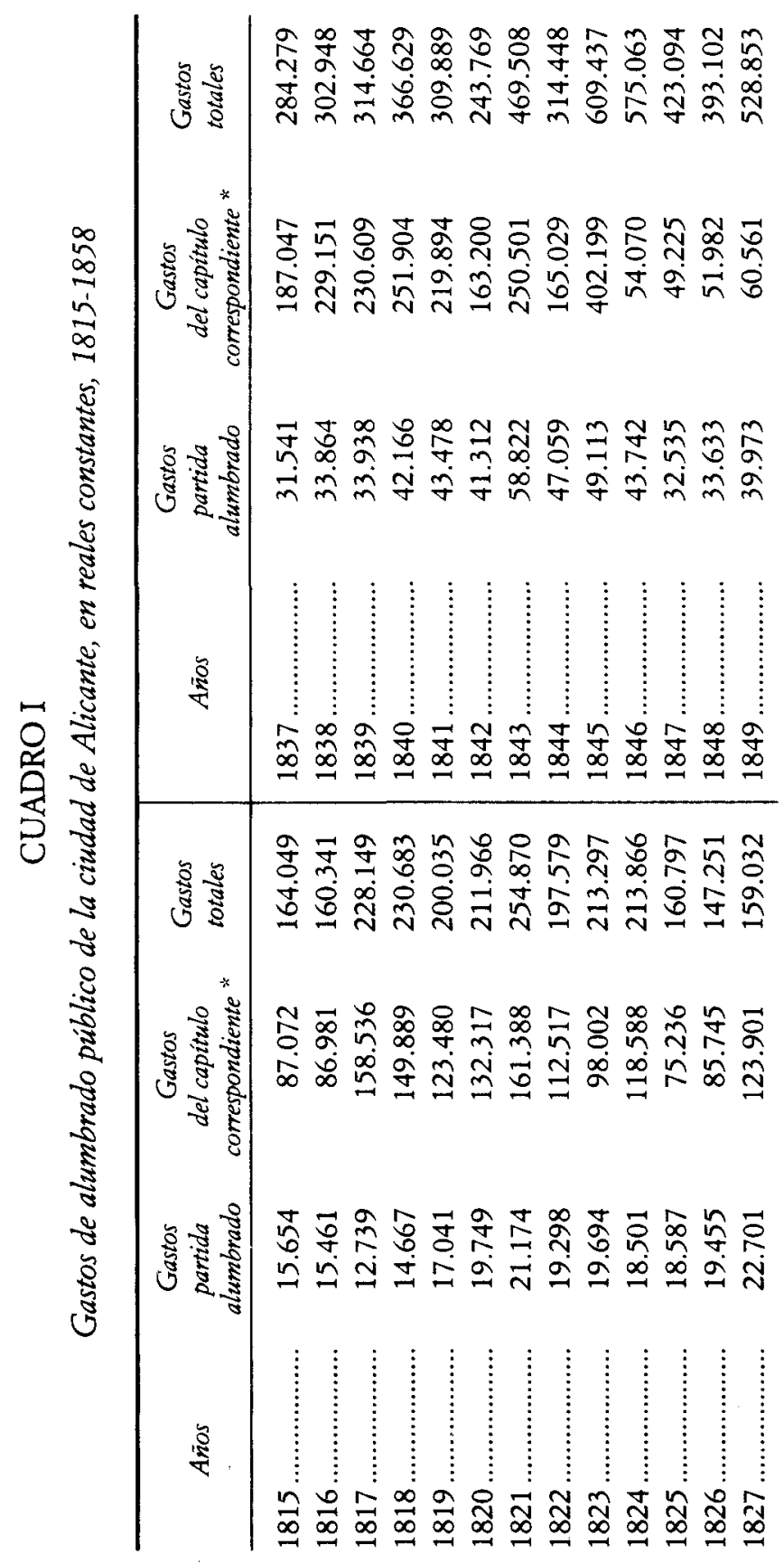




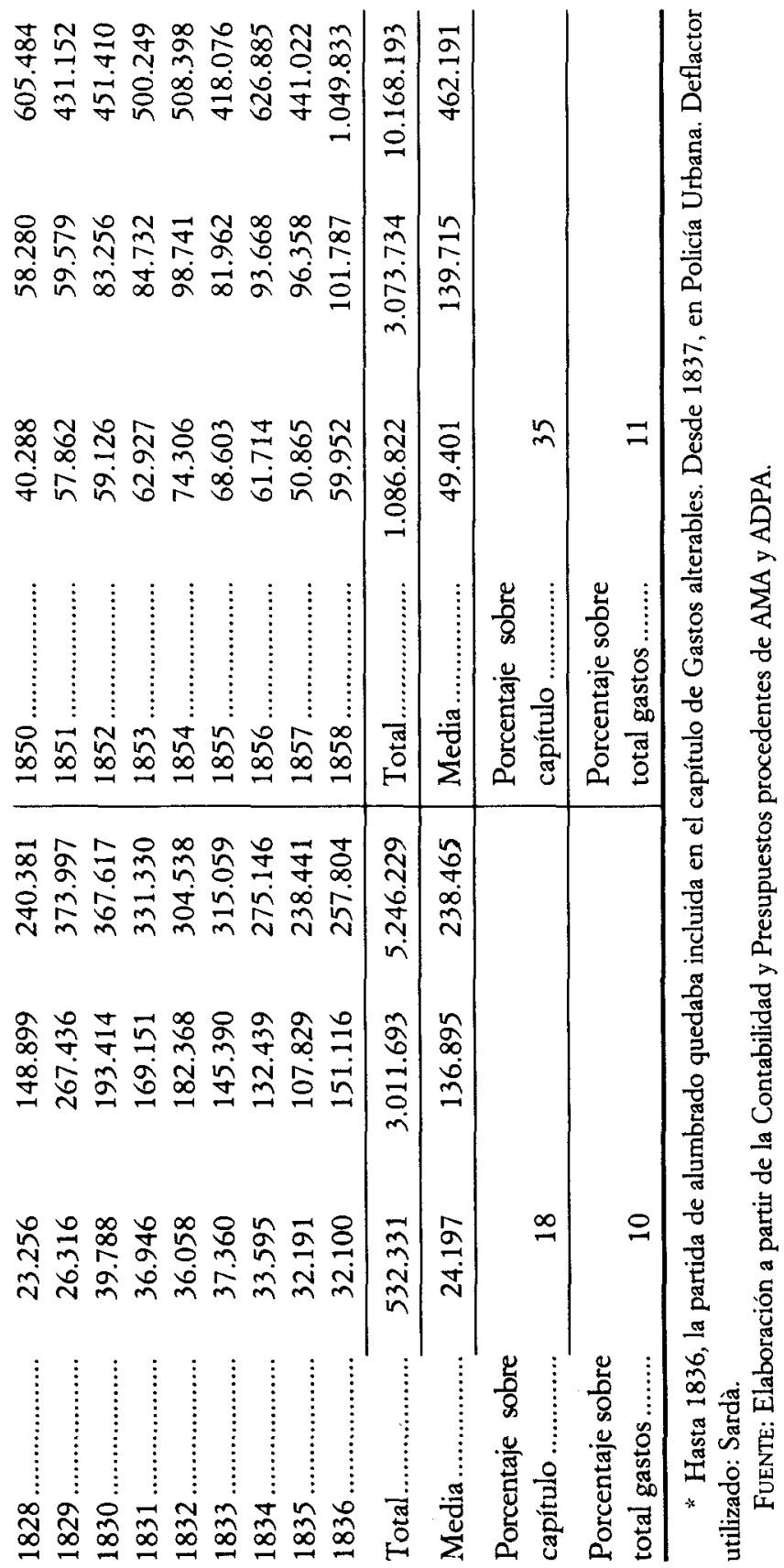


y mientras tuvo prerrogativa para ello, al arrendamiento en subasta pública con un precio fijo, normalmente por un período de tres años, aunque en algunos ejercicios la Corporación lo gestionó directamente. La cesión a la iniciativa privada era preferida por el Ayuntamiento, al permitirle despreocuparse de los riesgos de la oscilación al alza de los precios de los materiales, reformas y desperfectos de las farolas y, sobre todo, del aumento del precio del aceite, hecho que arruinó a algunos concesionarios del servicio. Por eso, en una de las cláusulas de los contratos de arrendamiento se prevenía que éstos se realizaban «a riesgo y ventura» del contratante. Las subastas a la baja tenían la ventaja para el Ayuntamiento de saber de antemano lo que le iba a costar el servicio durante todo el año. Pero, en cambio, a menudo iba en contra de los intereses de los ciudadanos, que se quejaban de la insuficiente y baja calidad de la prestación. El arrendador, claro está, perseguía maximizar sus beneficios, pero la morosidad e incluso el impago del servicio por parte del Ayuntamiento le afectaban muy negativamente. Los datos contenidos en el cuadro I ponen de manifiesto el esfuerzo inversor del Ayuntamiento en el alumbrado público alimentado por aceite durante la primera mitad del siglo XIX, aproximadamente ${ }^{13}$.

La comparación de las dos subetapas comprendidas en este período cronológico, la del Ayuntamiento absolutista entre 1815 y 1836 , y la de la Corporación liberal, más o menos a partir de 1837 y hasta 1858 , ofrece tres grandes rasgos. En primer lugar, la media de los gastos del subperíodo liberal (49.401 reales) duplicó la correspondiente al subperíodo absolutista

${ }^{13}$ A pesar de que el texto arranca en 1790 , sólo se dipone de datos sobre gastos de alumbrado desde 1815. Se debe de advertir que los datos de los subperiodos 1815-1836 y $1837-1845$ corresponden a gastos realizados estimados, porque la ley no tenía aún previsto las liquidaciones $y$, por lo tanto, no existen. Para la primera subetapa citada se han utilizado las Cuentas rendidas por el Ayuntamiento a la Contaduría de Propios y Arbitrios, que deben de ser consideradas con cautela porque el control de los fondos muricipales durante el Antiguo Régimen carecía de rigurosidad. Los datos de la segunda subetapa tampoco son gastos liquidados, aunque son más fiables debido al control que empezaron a ejercer las Diputaciones. La Instrucción de Contabilidad municipal de 1846, la Ley de Contabilidad de Bravo Murillo de 1850 y la creación del Tribunal de Cuentas del Reino de 1851 permitirían una mejor regulación y un mayor y más independiente control de las cuentas de las instituciones públicas, Ayuntamientos incluidos, obligándolas a presentar la liquidación. Consecuentemente, los gastos de este Ayuntamiento a partir de 1846, de forma intermitente, y desde 1859 , de forma continua, se corresponden con datos liquidados y realizados. Para más detalles sobre este asunto, véase Salort (1997). Los valores monetarios vigentes entre 1815 y 1874 , reales, escudos y pesetas, han sido convertidos a reales, para conseguir la uniformización, habida cuenta de que este último signo monetario abarcó la mayor parte de este tramo cronológico. 
(24.197 reales), lo que indica un mayor esfuerzo inversor del primero con respecto al segundo, hecho vinculado a una mayor preocupación por atender a las demandas sociales. En segundo lugar, el Ayuntamiento liberal concedió mucha más importancia a esta partida, porque su participación porcentual dentro del capítulo correspondiente, Gastos alterables en el Antiguo Régimen y Policía Urbana y Rural durante el liberalismo, también casi se duplicó, pasando de 18 a 35 puntos. Sin embargo, y por último, el peso de esta partida en el total de gastos se mantuvo sensiblemente en el mismo nivel ( 10 por 100 en el Ayuntamiento absolutista y 11 por 100 en el liberal). Pero hay que tener en cuenta que las Corporaciones burguesas asumieron más cargas propias, además de las delegadas por el Gobierno. Por lo tanto, el mayor esfuerzo inversor en este servicio se mantuvo. Por lo que respecta al servicio per capita, no se dispone de datos para el período absolutista. Para la etapa 1837-1858, la ciudad disponía de una luz para cada 80 habitantes, aproximadamente. Si comparamos la participación porcentual media de la partida del alumbrado a lo largo de todo el período ( 10 puntos), con lo consumido en los conceptos cuantitativamente más importantes en el mismo tramo temporal, se constata que representaba un poco menos de la cuarta parte del capítulo de los gastos del Ayuntamiento ( 36 puntos) y un peso casi similar a lo gastado en transferencias a la Hacienda central, por diversos conceptos, incluidas las deudas (12 puntos). Todos los demás capítulos del gasto se hallaban por debajo ${ }^{14}$.

\section{LA CONSOLIDACIÓN DEL AYUNTAMIENTO LIBERAL: DEL ALUMBRADO DE ACEITE AL DE PETRÓLEO Y GAS (1859-1874)}

A partir de la segunda mitad del siglo XIX, al compás de la institucionalización del régimen liberal y de los cambios económicos y demográficos, los Ayuntamientos asumieron nuevas atenciones, consolidaron algunas de las ya existentes y procedieron a la modernización de ciertos servicios públicos. Este proceso se llevó a cabo, en general, mediante la concesión de la gestión de algunas provisiones a la iniciativa privada, habida cuenta de la exigencia de grandes inversiones y de la complejidad que presentaba su gestión industrial y comercial ${ }^{15}$.

14 Véase Salort (1997).

15 Para las razones de la concesión de la gestión privada en algunos servicios públicos, por parte de los Ayuntamientos, véase Comin (1996) y Núnez Romero-Balmas (1996b). 
En el caso del alumbrado público, el Ayuntamiento de esta ciudad inició el proceso de sustitución del aceite por el petróleo y el gas, con un evidente retraso no sólo respecto de los países más avanzados de Europa, sino también en relación con las principales ciudades españolas ${ }^{16}$. En 1846 , por primera vez, y después, en 1854, hubo intentos de cambio en el sentido antes apuntado. Sin embargo, no se materializaron por dificultades financieras ${ }^{17}$. Por lo tanto, se siguió con el proceso de mejorar el alumbrado por aceite, acrecentando el número de farolas. Finalmente, el 23 de diciembre de 1856, en sesión extraordinaria del Ayuntamiento asociado a los mayores contribuyentes, se acordó firmar un convenio de arrendamiento del alumbrado a gas con Melitón Martín y Compañía de Madrid. El 27 de enero de 1857 se firmó el contrato escriturado, que establecía el monopolio del suministro durante veinticinco años a esta empresa y que obtuvo la conformidad del Gobierno por la Real Orden de 22 de junio de 1857 , aunque con reticencias, al no haberse cumplido las formalidades de la Ley de $1852^{18}$. Sin embargo, casi inmediatamente, el 9 de febrero de

${ }^{16} \mathrm{El}$ alumbrado por gas se fue extendiendo por Europa a partir del primer tercio del siglo xTx. En España, Barcelona dispuso de fábrica de gas en 1842, Valencia en 1843, Madrid en 1846, Bilbao en 1847 y Sevilla en 1853. Véase Sudrià (1983).

17 La primera noticia acerca de este cambio se sitúa en 1846, año en que la Corporación Municipal pide autorización al Gobernador para dicho objetivo. Informado por el Consejo Provincial, el Jefe Político concedió permiso para que aquélla procediera a arrendar en pública subasta el servicio por gas. Sin embargo, este intento no se concretó. Siguiendo con el intento, el 24 de febrero de 1854 el alcalde pidió a sus homólogos de Madrid, Barcelona, Zaragoza, Valencia, Cádiz, Málaga y Girona los pliegos de condiciones bajo las cuales estaba establecido o se pensaba establecer el alumbrado por gas. Y en Cabildo de 22 de junio de 1854 se aprueba un proyecto de contrato con José Martín, ingeniero de Madrid que con posterioridad se convertiría en socio de la empresa Melitón Martín y Compañía de Madrid, para la instalación del alumbrado a gas, que, elevado al Gobernador en la misma fecha, fue aprobado. Sin embargo, las dificultades financieras dieron al traste con el intento.

${ }_{18}$ Según la contrata, la empresa corría con la construcción y conservación del gasómetro y las canalizaciones necesarias; en el plazo de tres años debía de completar el suministro total de trescientas luces; quedaba obligada a instalar y conservar ios enseres para la conducción y distribución del gas; debía de suministrar 4,75 pies cúbicos de gas por hora; se comprometía al suministro de gas y efectos para el alumbrado interior del Ayuntamiento; debía de asegurar el alumbrado por aceite mientras se mantuviera; y, finalmente, no podía exigir indemnización, salvo catástrofes, ni variar la tarifa y debía de indemnizar al Ayuntamiento con un montante doble de la tarifa establecida si faltaba el servicio, salvo causa mayor. La Corporación abonaría tres maravedies por luz y hora, durante los veinticino años.

El 14 de julio de 1857 el Gobierno autorizó la instalación de la fábrica en la $2 .^{2}$ zona de ensanche, en los terrenos adquiridos al comerciante y miembro de una de las familias más influyentes de la ciudad, José G. Amérigo. Entre 1858 y 1860 se realizaron los planos y se fijaron las calles (los viarios más céntricos) por donde se iniciaría la distribución de gas. Mientras tanto, la Compañia General de Crédito en España había sustituido al anterior 
1857, la citada firma cedió esta contrata a la Compañía General de Crédito en España, cuyo socio principal era el financiero francés Alfred Prost. Queda clara la pericia técnica y la insuficiencia financiera de la empresa de Melitón Martín, que actuaba como mero intermediario, y que debía de recurrir al capital extranjero. Por ello mismo comunicaban al Ayuntamiento que «nosotros, sin embargo, quedamos encargados de la construcción de la fábrica y del establecimiento del nuevo alumbrado, en nuestra calidad de ingenieros» 19 .

Cuatro años después, en 1861, la Compañía empezó a suministrar gas. Pero inmediatamente surgieron las primeras desavenencias con el Ayuntamiento. Su Comisión del Alumbrado denunciaba a la Compañía por el incumplimiento en los plazos de construcción de la fábrica de gas e instalación de las tuberías de distribución y por el abandono del alumbrado por aceite; exigía reformas del contrato que permitieran la ampliación del número de luces; y amparaba las quejas de algunos particulares contra el monopolio que la empresa ejercía de facto, en relación al suministro de accesorios del alumbrado a gas ${ }^{20}$. Por su parte, la empresa argumentaba la demora en disponer de los terrenos para la instalación de la fábrica. El Administrador-Director de la Compañía General de Crédito en España, Adrián Guilhou, exponía al Ayuntamiento que «no pueden ocultarse los

representante de la empresa, Gabriel Ravello, por Jorge P. Moreno, vinculado a J. Bautista Lafora. Los tres pertenecían a la burguesía comercial alicantina. AMA. Alumbrado. Años 1856-1858. Legajo 1, núms. 28, 29 y 30. Alumbrado. Años 1859-1862, Legajo 1, núm. 34: «Contrato para el alumbrado público por gas. Correspondencia oficial referente a la ejecución».

${ }^{19}$ Según M. ${ }^{\mathrm{a}}$ T. Costa, en 1857, la Compañía General del Crédito de los Prost «solicitó un nuevo desembolso del 20 por 100 del capital, o sea de 100 francos franceses, por acción, con el propósito de realizar el suministro de alumbrado de gas en Valladolid, Burgos, Albacete, Cartagena, Alicante, Jerez y Pamplona. La inversión inicial fue de unos cuatro millones de pesetas». Véase Costa (1981), p. 53, y Sudrià (1983).

${ }^{20}$ La Comisión demandaba la ampliación del número de luces hasta las 400 ; exigía que todos los mecheros fueran de $1 .^{\text {a }}$ clase y de consumo de 150 litros por luz y hora y que el Ayuntamiento abonara 13 céntimos de real por luz y hora y los particulares 47 reales por cada 1.000 pies cúbicos españoles de gas, el precio máximo. Asimismo, algunos particulares, como los empresarios del Teatro Principal, se quejaban del monopolio que, de hecho, ejercía la Compañía en el suministro de los accesorios del alumbrado a gas, que se negaba a suministrar fluido al haber recurrido los citados propietarios a otro proveedor de la plaza, Bartolomé Maylín, arrendatario habitual del servicio de alumbrado público por aceite. La Comisión del Alumbrado de la Corporación informaba, a este último respecto, que la posición era «insostenible con la inteligencia que le da el representante de la empresa, por ser contraria a la libertad industrial y comercial que establecian las leyes de la fabricación y venta de aparatos», dando la razón a los recurrentes. La documentación sobre las protestas de la Comisión del Alumbrado y las quejas de los propietarios del Teatro Principal, en AMA. Alumbrado. 1861. Legajo 1, núm. 33 . 
mil inconvenientes con que tropieza una Empresa de esta especie en un país donde se carece de los elementos necesarios para llevarla a cabo». Ni una palabra de la ampliación, ni de las prácticas monopolísticas ilegales, que utilizaba para compensar el insuficiente rendimiento de la fábrica ${ }^{21}$.

En cualquier caso, en 1861, el alumbrado público de esta ciudad, que contaba con algo más de 31.000 habitantes, se componía de 188 luces de gas y 99 farolas de reverbero y 114 farolas pequeñas por aceite y petróleo. Como el sistema resultaba insuficiente, a principios de 1862 el Ayuntamiento pidió a la concesionaria la ampliación de la red de alumbrado a gas al resto de la ciudad, que aún no contaba con ella. Significativamente, la empresa contestaba que esta propuesta debía de ser estudiada por el Consejo de Administración, habida cuenta que

«la parte de la población que aún está sin canalizar, es de escasa importancia relativamente al alumbrado particular puesto que la tubería, en su mayor trayecto, quedará exclusivamente destinada a alimentar el alumbrado público, el que lejos de proporcionar beneficios, ocasiona pérdidas a la explotación de las Fábricas» ${ }^{22}$.

La debilidad del consumo privado y las deudas del Ayuntamiento constituirían el talón de Aquiles en la rentabilidad de las fábricas de gas. Por ello, la empresa endurecía las condiciones para la expansión de la red, exigiendo la ampliación de la concesión a quince años más. El nuevo contrato se firmó el 30 de noviembre de 1863 pero fue anulado por la Real Orden de 20 de abril de 1865, porque alteraba el plazo de concesión del de 1857 sin haber mediado subasta pública. Al mismo tiempo, el Gobierno conminaba a la Companía a que ampliara la red, bajo las condiciones estipuladas en 1857. Sin embargo, la empresa no se consideraba obligada a cumplir estos requerimientos, a no ser con «condiciones especiales», ya que de lo contrario sufriría «graves perjuicios a sus intereses» ${ }^{23}$.

${ }^{21}$ El retraso se debió a la tardanza en la demolición de las murallas, que trastocó la ubicación de la fábrica fuera del casco urbano. AMA. Alumbrado. Años 1859-1861. Legajo 1 , núm. 33.

${ }_{22}$ Respuesta del representante de la Compañía y director de la fábrica, J. P. Moreno, a la solicitud del Ayuntamiento. AMA. Alumbrado. 1862. Legajo 1, núm. 34.

${ }^{23}$ En octubre de 1863 se redactó un nuevo Convenio para la citada ampliación, en el que la Compañía «teniendo en cuenta la poca importancia relativamente al alumbrado de edificios particulares que tienen las (...) calles [objeto de ampliación] y las dificultades que presentan para el establecimiento de la tubería y colocación de aparatos», exigía la ampliación del plazo de la concesión hasta los cuarenta años, es decir, quince años más; el establecimiento del mismo número de luces de gas que las existentes entonces, llegando, por lo tanto, a las 600 en total; el consumo medio de cada mechero por hora debía de 
Sin embargo, las necesidades de una ciudad que a partir de los años sesenta del siglo XIX no dejó de crecer (la población pasó de 31.162 habitantes en 1860 a 50.142 en 1900) y el inicio del turismo explican nuevos intentos de ampliar la red con esta concesionaria, incrementando el precio ${ }^{24}$.

Los impagos de este Ayuntamiento debieron de influir en la decisión de la Compañía General de Crédito de vender esta fábrica de gas a la Sociedad Holandesa del grupo Stockman, establecida en Rotterdam. Habían transcurrido sólo ocho años desde la concesión y cuatro desde que inició el suministro. La venta se materializó el 11 de septiembre de 1865 y actuó de intermediario el francés Charles Blanchat y Blondel. El precio del traspaso, que incluía la instalación con todos los derechos y obligaciones, ascendió a 1.700 .000 reales ${ }^{25}$. En 1866 el Ayuntamiento firmó otra contrata con la nueva concesionaria, para prestar servicio a toda la población (600 luces), incrementando el precio. Tenía carácter privado, para sortear las formalidades de la subasta, y no alteraba el plazo de la concesión. Este convenio sí que fue autorizado por el Gobierno ${ }^{26}$. Las dificultades financieras de la empresa explican que escasamente dos años

ser, como mínimo, de 120 litros, los mismos que entonces estaba suministrando; la duración del alumbrado tenía que ser, al menos, de 2.400 horas anuales; el precio sería de 132 milésimas de real por cada luz y hora de encendida y, finalmente, el material utilizado debía de ser el mismo que el ya existente, salvo en algunos puntos accidentados, donde se colocarian tuberias de plomo, en vez de las de palastro. AMA. Alumbrado. 1863. Legajo 1, núm. 35. Año 1865. Legajo 1, núm. 37.

${ }^{24}$ Así, entre 1863 y 1865 , el Ayuntamiento firmó un convenio provisional con la Compañía General, dependiente de la confiada aprobación del de 1863, para alumbrar el sector de la playa del Postiguet y del Muelle, con un aumento de 20 céntimos de real por luz y hora. Desautorizada la contrata de 1863, el Ayuntamiento consiguió que el Gobernador permitiera continuar alumbrando las zonas citadas, ya instaladas, hasta el final de la temporada de los baños de mar. Después, se cortó el alumbrado. AMA. Alumbrado. Año 1863. Legajo 1, núm. 35. Año 1865. Legajo 1, núm. 37.

${ }_{25}$ Según Costa, en 1863, «tan sólo dos años después de la puesta en funcionamiento de forma definitiva de todas las fábricas de gas (...), comenzó a correr el rumor de la venta de éstas (...). La situación financiera de la Compañía General le obligó a subastar el 6 de mayo de 1865 las Sociedades del Gas». Véase Costa (1981), p. 53. La Escritura de compraventa de la fábrica de gas de Alicante se firmó en Madrid el 11 de septiembre de 1865 . El 17 de octubre de 1865 la Compañía de Crédito comunicaba al Ayuntamiento la venta y el 21 la Sociedad Holandesa escribía a la Corporación municipal para presentarse. Esta Sociedad, con un capital de 3.500 .000 florines, según Costa (1981), era fabricante de material para la producción de gas y concesionaria del servicio de alumbrado en diversas ciudades de los Países Bajos según Sudrià (1983), y también de núcleos urbanos del norte de África. Para el proceso de compraventa de la fábrica alicantina, AMA. Alumbrado. Año 1865. Legajo 1, núm. 37.

${ }_{26}$ Los términos de este convenio, firmado en 5 de abril de 1866, establecía un aumento de 300 luces en una primera fase, que se incrementarian después, hasta llegar a las 600 luces. El precio fijado para las luces del primer plazo sería de 132 milésimas de real por 
después, en 1867, la Sociedad Holandesa arrendara la fábrica a Carlos Lebon por un período de diez años. En su escrito al alcalde, la Sociedad Holandesa decía que «Monsieur Lebon se propone explotar esta Fábrica bajo una grande escala y extender las canalizaciones, trabajos $(\ldots){ }^{27}$. En 1867, la ciudad, con una población de 30.000 habitantes, contaba con 446 faroles de gas, 81 de reverbero por petróleo y 93 pequeños por aceite. A partir de 1868 se inició la instalación del alumbrado en el Malecón, la actual Explanada.

En 1876, finalizado el arrendamiento con Lebon, la Sociedad Holandesa retomó las riendas. Pero la morosidad municipal en los pagos la llevó a deshacerse de la factoría, vendiéndosela a la Compañía Madrileña de Alumbrado y Calefacción por Gas, en 1880, tan sólo tres años después de esta nueva y desastrosa experiencia. Esta nueva concesionaria endureció las condiciones de la contrata en los plazos (cuarenta años); en la exención de recargos municipales; en los precios; en los suministros mínimos; en las hipotéticas indemnizaciones por impagos y en la provisión de gas a particulares ${ }^{28}$. A pesar de los cambios de las concesionarias, el proceso de ampliación del alumbrado por gas en esta ciudad no se detuvo y en 1890 contaba ya con 809 luces por este sistema, para una población de 45.000 habitantes ${ }^{29}$.

luz y hora y el de las luces posteriores 120 milésimas de real por luz y hora. El consumo medio de cada mechero no podía ser inferior a 120 litros por luz y hora, sin alteración con respecto a los que ya funcionaban. Las nuevas zonas objeto de esta ampliación eran los barrios de Santa Cruz, San Antón y San Francisco, que habían quedado enmarcados dentro del casco urbano, como fruto del derribo de las murallas. AMA. Alumbrado. Año 1867. Informe de la Comisión de Alumbrado. Legajo 1, núm. 39. Se autorizó por la Real Orden de 3 de agosto de 1867.

${ }^{27} \mathrm{El}$ arrendamiento se inició el día 1 de julio de 1867. AMA. Alumbrado. Año 1867. Legajo 1, núm. 39.

${ }^{28}$ El contrato entre el Ayuntamiento y la Compañía Madrileña de Alumbrado y Calefacción por Gas fue firmado en Alicante en 28 de julio de 1880 y aprobado por el pleno municipal el día 7 de noviembre siguiente. Aleccionada por las negativas experiencias de las anteriores empresas, esta concesionaria impuso al Ayuntamiento un período de privilegio en exclusiva de cuarenta años; la exención de recargos locales sobre los materiales necesarios para la fabricación del gas; el precio para el alumbrado público quedó fijado en 22,5 céntimos de peseta por luz y hora; el Ayuntamiento quedaba obligado a consumir un mínimo anual de 100.000 metros cúbicos de gas para el alumbrado público; y en el caso de que no se le pagara durante cuatro meses, recibiría un 6 por 100 de intereses anuales sobre el capital adeudado; si la cantidad no satisfecha alcanzaba las 30.000 pesetas, la compañia podía dejar de suministrar energía. En cuanto al consumo particular, el precio se elevaba a 1,75 reales por metro cúbico y se debía de abonar tres meses adelantados.

29 «Relación detallada de los faroles de alumbrado por gas existentes en esta capital, 
El proceso de ampliación del alumbrado a toda la ciudad se hizo con dificultades y controversias, algunas ya vistas, entre el Ayuntamiento y las sucesivas empresas. En general, la Corporación municipal denunciaba el incumplimiento de los plazos para el establecimiento del alumbrado a gas y la contravención, al alza, de las tarifas fijadas en los diversos convenios ${ }^{30}$. Las quejas de las concesionarias contra el Ayuntamiento, que a la postre ayudan a explicar los sucesivos cambios de titulares de la fábrica de esta ciudad, y probablemente de otras, se centraban en los impagos municipales. Así, en 1863, dos años después del inicio del suministro de gas, el director de la fábrica, entonces de la Compañía General de Crédito, se lamentaba al Ayuntamiento porque éste no había desembolsado ninguna cantidad por el traslado de tuberías, ni había percibido un real por los aparatos instalados en el edificio municipal, y le rogaba que le pagase, habida cuenta de que se tenía que financiar con la actividad de la propia fábrica, indicando la falta de liquidez de la Compañía ${ }^{31}$. Con mayor rotundidad se expresaba el director de la Compañía en España, Guilhou, al comunicarle al alcalde, en 1865 , cuando ya había tomado la decisión de vender la fábrica, que

«la situación excepcional en que se encuentra la Compañía General de Crédito en España, no le permite hacer, como hasta aquí, los adelantos de fondos necesarios a sus fábricas de gas para el pago del personal, compra de carbones y otros objetos de primera necesidad. Es, pues, indispensable que dichos establecimientos se basten a sí propios y hallen en la ordenada gestión de los negocios que les están encomendados, los recursos que puedan necesitar; pero esto será imposible a todas luces si las facturas mensuales que presentan a las respectivas corporaciones municipales, no son satisfechas con exactitud. Ya se experimenta el atraso de algunas mensualidades y el desconcierto que de esto resulta llegará a ser tan perjudicial para el buen servicio del alumbrado, como dañoso para los intereses de la Compañía. El Consejo de Administración de la misma no puede explicarse tal retardo en el pago de las facturas por los respectivos Ayuntamientos, cuando el

en 31 de diciembre de 1890», hecha por la Compañía Madrileña el 8 de enero de 1891. AMA. Alumbrado. Año 1891. Carpeta núm. 25.

${ }^{30}$ AMA. Alumbrado. Año 1867. Informe de la Comisión de Alumbrado. Legajo 1, núm. 39.

${ }^{31}$ El 16 de mayo de 1863, el director de la fábrica escribía al alcalde diciéndole que «no puedo proceder a nuevos trabajos (...) por falta de recursos (...) [y que] aún no he recibido nada a cuenta de lo aparatos que hace ya dos años fueron colocados por obreros de esta Fábrica en esa casa de Ayuntamiento, y como quiera que este establecimiento no cuenta para atender a sus necesidades con más recursos que los suyos propios, me veo forzado a llamar la atención de V. E. para que se digne disponer me sea pronto satisfecha la factura del suministro y colocación de tales aparatos». AMA. Alumbrado. Año 1863. Legajo 1, núm. 35. 
gasto del alumbrado está comprendido en el presupuesto municipal y éste aprobado por el Gobierno».

Pedía al alcalde que ordenara el pago de las deudas acumuladas, «con lo cual evitará grandes perjuicios al servicio del alumbrado y a esta Compañía: ${ }^{32}$. Si el Consejo de Administración de la Compañía no podía entender los impagos municipales, el análisis de la Hacienda municipal de esta ciudad esclarece el asunto. Su permanente agobio financiero, manifiestado en las abultadas cifras de las resultas en los ingresos, con un alto grado de desviación entre lo presupuestado y lo liquidado y que forzosamente se trasladaban a su homólogo capítulo de los gastos, explica los recortes del gasto y la acumulación de deudas por muchos conceptos, entre ellas las del alumbrado ${ }^{33}$. También la Sociedad Holandesa, nueva concesionaria desde 1865, sufrió el problema de los impagos municipales. A principios de 1867 esta empresa exigía a la Corporación municipal que se le abonasen las deudas puesto que suponían una

«suma considerable, cuya falta paraliza las operaciones de la fábrica de gas (...) [y] le es indispensable a la Sociedad Holandesa recibir estos fondos para las necesidades de la fabricación de gas, que exige provisiones que hay que pagar al contado y para los cuales no podemos prever si recibiremos el dinero que se nos debe».

Una vez más, la falta de liquidez. El Ayuntamiento contestaba que no podía pagar pero que en el futuro «será religiosamente atendido con preferencia» este epígrafe de la deuda ${ }^{34}$. Esta sociedad, desde luego, no confió demasiado en las promesas de este Ayuntamiento - y es de suponer que en las de otros-, por lo que arrendó la fábrica, como ya se ha dicho, a Carlos Lebon. Tampoco al nuevo gestor le faltaron los problemas de los impagos. Casi tres meses después de haberse hecho cargo de la fábrica Carlos Cauchois, Administrador de la misma y representante de Lebon, escribía al Ayuntamiento recordándole que le debía 103.331 reales, sin contar con la mensualidad corriente, y que

«habiendo transcurrido ya largo tiempo sin que la Fábrica haya percibido nada por este concepto el exponente se ve en la precisión de hacerlo presente

${ }^{32}$ AMA. Alumbrado. Año 1865. Legajo 1, núm. 37. Carta del director de la Compañía General de Crédito en España al alcalde, de 8 de agosto del año citado.

${ }^{33}$ Para la insuficiente financiación de esta Hacienda municipal, desviaciones de ingresos y gastos, nivel de endeudamiento y déficit de caja entre 1846 y 1874, véase Salort (1997).

${ }^{34}$ AMA. Alumbrado. Año 1867. Legajo 1, núm. 39. 
a V. E. manifestándole que no contando este establecimiento de su cargo con más recursos que los que produce su explotación, se encuentra en la angustiosa situación de no poder continuar prestando el servicio del alumbrado público si $\mathrm{V}$. E. penetrado de la justicia de su demanda no le presta el auxilio debido, disponiendo que se le satisfaga el importe de cuanto se le adeuda [a fin de evitar] el inmenso disgusto de tener que atenerse a la condición del contrato para el servicio del alumbrado público por gas, en la que se expresa que la fábrica no vendrá obligada a continuar prestando el referido servicio si transcurren dos meses sin que se le satisfaga su importe» (...) [exigía, pues, que se le pagase la cantidad mencionada] «así como 101 reales y 94 céntimos que se le han impuesto de recargos de contribuciones por no haber podido contar a tiempo con los fondos necesarios para pagar la cuota que le ha correspondido por no haberle satisfecho V. E. ni una mínima parte de la suma que le adeudas ${ }^{35}$.

Para paliar el problema y evitar el corte del suministro, el Ayuntamiento autorizó a la Comisión de Presupuestos para buscar empréstitos con carácter urgente. Algo se solucionó, pero era muy insuficiente ${ }^{36}$. Con todo, la situación empeoró con la llegada del Ayuntamiento Popular, a partir de $1869^{37}$. A principios de 1869 , el director de la fábrica enviaba al alcalde un «Estado de las deudas» acumuladas desde 1866, desolador tanto para el Ayuntamiento como para la empresa, pues ascendía a 151.723 reales ${ }^{38}$. El director de la fábrica pedía que, al menos, se le pagasen los atrasos de 1868 ,

«cantidad que me es muy necesaria para atender a las provisiones de carbón y reparaciones urgentes» (...) [y que] «en lo venidero se me pague con regularidad conforme lo indica el contrato, las mensualidades vencidas y que por lo atrasado de 1866 y 1867, el respetable Consejo que V. S. tan

${ }^{35}$ AMA. Alumbrado. Año 1867. Legajo 1, núm. 39.

${ }^{36}$ De nuevo en 1868 , el director de la fábrica volvía a reclamar a la Corporación que pagase la deuda que hasta el citado año ascendía a la notable cantidad de 126.270 reales. AMA. Alumbrado. Año 1868. Legajo 1, núm. 40.

${ }^{37}$ En principio, los munícipes progresistas, siempre más conscientes de las necesidades de la población, aunque también menos rigurosos a la hora de contar efectivamente con recursos para cubrir los servicios, ordenaron mantener durante más horas el alumbrado, también por motivos de seguridad, sin duda. Pero los avisos del director de la fábrica respecto de las deudas acumuladas y el aumento del gasto corriente les hizo pronto desistir de tales medidas. AMA. Alumbrado. Año 1869. Legajo 1, núm. 41.

${ }^{38}$ Este total se desagregaba de la siguiente manera: la deuda atrasada de 1866-1867 ascendía a 87.035 reales; la de 1868 contabilizaba 53.771 reales y sólo del mes de enero de 1869 se debían 10.916 reales. 
dignamente preside, en el próximo cabildo determine según los recursos del Ayuntamiento un modo de amortizar dicha deuda ${ }^{39}$.

Pero el problema era irresoluble y se agudizó con el tiempo. Un año después, en 1870 , el director de la fábrica manifestaba la falta de liquidez de la misma por impagos municipales en un «Estado de los créditos [acumulados] en contra del Ayuntamiento», que ascendían ya a 267.626 reales ${ }^{40}$. El Ayuntamiento decía que confiaba en haber culminado con éxito el reparto del Impuesto personal, que debía de compensar la pérdida en la recaudación de los abolidos gravámenes sobre el consumo, para satisfacer las deudas y los pagos corrientes. Pero es conocido el fracaso del establecimiento de este gravamen, a nivel general y en la Hacienda local, que produjo un descenso en los ingresos y obligó a un recorte de los gastos ${ }^{41}$. Mientras tanto, y ante los problemas del servicio por gas, el Ayuntamiento prestaba alumbrado por petróleo ${ }^{42}$.

La situación se agravó al año siguiente. En agosto de 1871, la Compañía le comunicaba al Gobernador que las deudas del Ayuntamiento ascendían

${ }^{39}$ El director de la fábrica, además, pedía al Ayuntamiento moderación en el gasto del alumbrado a gas, aplazamiento de cualquier proyecto de ampliación de la red y prórroga de la concesión por diez años más. AMA. Alumbrado. Año 1869. Legajo 1, núm. 41.

40 A Lebon padre e hijo y Compañía se le debían, desde julio de 1867, 179.105 reales; a la Sociedad Holandesa, mientras la fábrica corrió de su cuenta, 87.035 reales; y desde enero hasta junio del año corriente, otra vez a Lebon, 1.486 reales. La situación de la fábrica era tan desesperada, que ya a principios de 1870 el director pedía dinero al Ayuntamiento para pagar los fletes de los buques que transportaban el carbón a la ciudad. El estado de las deudas en AMA. Alumbrado. Año 1870. Carpeta núm. 1. Cartas del director de la fábrica, José Guillem, al Ayuntamiento, de 12 de junic y 9 de julio.

${ }^{41}$ El alcalde manifestaba al director de la fábrica, el 15 de febrero, que «con harto sentimiento mío no me es posible satisfacer a V. tan pronto como deseo, el importe del consumo del gas en los meses de diciembre y enero pasados, pero aseguro a V. que tan pronto como los ingresos de esta Corporación permitan le será satisfecha la cantidad que tan justamente reclama y se dispondrá el medio más conveniente para ir amortizando la deuda atrasada. Espero se hará $V$. cargo de la angustiosa situación porque atraviesa este municipio, que aunque animado del mejor deseo, se ve imposibilitado de cubrir sus más sagradas atenciones». Nuevamente el alcalde, en 9 de julio, le contestaba al director de la fábrica: «pero en vista de que no ha sucedido así [la recaudación dei Impuesto personal], debo decir a V. que se tendrá muy presente la justa reclamación de esa Compañía y se destinarán los primeros fondos que se recauden en atender tan legítima petición. Mientras este caso llega, no hay inconveniente en que se le reconozca el crédito por el Ayuntamiento, si V. lo juzga necesario». AMA. Alumbrado. Año 1870. Carpeta núm. 1. Para mas información acerca del fracasado ensayo del Impuesto personal de la Hacienda central, véase Comín (1997) y para el frustrado intento de esiablecer los arbitrios recargados sobre aquél en esta ciudad, véase Salort (1997).

${ }^{42}$ El Ayuntamiento procedió a una subasta para el ejercicio de 1870-1871, que incluía 90 faroles grandes y 93 pequeños, y que se concedió a Rafael Marimón, por un montante de 23.700. AMA. Alumbrado. Año 1870. Carpeta núm, 1. 
ya a la muy respetable cantidad de 376.530 reales, y amenazaba con cortar el fluido a las oficinas de las Casas Consistoriales. La autoridad provincial pedía información a la Corporación y le exigía que hiciera lo imposible para evitar el apagón general. El alcalde contestaba lamentándose por la insuficiencia de recursos, pero el Ayuntamiento presupuestó urgentemente 35.000 pesetas para el año en curso y consignó 60.000 pesetas para la amortización de las deudas. Esta medida, sin embargo, no apaciguó a la concesionaria, que cortó el suministro de gas para las oficinas municipales ${ }^{43}$. Inmediatamente, además, la Compañía se quejó al Ministro de la Gobernación comunicándole que iba a cortar todo el suministro y éste telegrafiaba al Ayuntamiento para que arbitrara medios con que satisfacer las deudas y pagar los gastos corrientes. En el Cabildo extraordinario de 23 de agosto de 1871, después de reconocer la carencia de fondos y la situación deficitaria, la Corporación acordaba: ceder a la concesionaria las láminas instransferibles y los intereses rendidos en los dos últimos años, como abono en cuenta de la deuda acumulada; consignar en el Presupuesto alguna cantidad para normalizar los pagos; y reducir el número de luces ${ }^{44}$. Mientras tanto, el proveedor del alumbrado a petróleo dejaba de prestar el servicio, también por las deudas.

Hasta 1874 se agudizaría la situación entre una Hacienda municipal, indigente y agobiada por las deudas, y la empresa concesionaria, carente de liquidez, que mezclaba las amenazas de corte de fluido con las súplicas

${ }^{43}$ El Gobernador pedía información sobre el estado financiero y las asignaciones para alumbrado. En su respuesta, de 26 de agosto de 1871, el alcalde hablaba de las turbulencias del momento, que le había obligado a prorrogar el Presupuesto del año anterior; y que el Ayuntamiento sufría una insuficiencia presupuestaria por el fracaso del Impuesto personal, por la resistencia de los contribuyentes; en cuanto a la correcta distribución de los fondos expresaba: «ंPero de qué fondos, si no se conocen? ¿De qué fondos, si se ignora con los que puede contar?»; en relación a la partida del alumbrado, comunicaba que no había ninguna cantidad para los gastos corrientes, tan sólo algo para amortizar las deudas; además, el Ayuntamiento había tenido que correr con los gastos derivados de la epidemia de fiebre amarilla de 1870, que, además, había reducido la capacidad recaudatoria. El alcalde añadía que «además, un sistema administrativo no se cambia radicalmente en un día». AMA. Alumbrado. Año 1871. Carpeta núm. 4.

${ }^{44}$ El Ministerio accedió, incluso, a autorizar la conversión de las suscripciones intransferibles procedentes de la desamortización, en 1855-1858, de los capitales de censos de la Corporación. La renta de las cinco láminas intransferibles de la Deuda, en que habían acabado convertidos los 193.804 reales producidos en la venta de los capitales de censos, oscilaba en torno a los 4.000 reales anuales. AMA. Alumbrado. Año 1871. Carpeta núm. 4 y Cabildo extraordinario de 23 de agosto de 1871. 
para que se le abonase alguna cantidad ${ }^{45}$. La precariedad financiera local tenía un impacto tan perverso en las compañías arrendatarias, que llegaba incluso al extremo de impedirles la compra de carbón. Además, el incumplimiento de los compromisos por parte del Ayuntamiento afectaba, asimismo, a los importadores locales de carbón Newscastle ${ }^{46}$. La fábrica no llegó a cerrarse pero durante 1874 siguió su proceso de descapitalización, hasta el extremo de que Lebon la abandonó a mediados de este año ${ }^{47}$. En 1876 la Sociedad Holandesa, que de nuevo gestionaba la fábrica, pidió al Ayuntamiento el montante de las deudas contraídas por los gestores anteriores por cuotas de usufructo, esperando normalizar las relaciones ${ }^{48}$. Sin embargo, no fue posible. En 1879, el Ayuntamiento debía a la Sociedad

${ }^{45}$ Así, a principios de 1872 , la fábrica, confiando en las promesas realizadas a fines del año anterior por el Ayuntamiento, servía de nuevo el alumbrado a las oficinas municipales. Pero ante un nuevo incumplimiento, procedía al corte de algunas luces y suministraba menos cantidad de gas de la establecida en el convenio para las otras. $Y$ de nuevo advertía que iba a dejar la ciudad sin luz. Un Informe de la Comisión de Alumbrado atribuía la actitud de la empresa a que el Ayuntamiento le debía ya 335.772 reales, y proponía una serie de reformas. En primer lugar, suprimir luces en el centro de la ciudad y conservar y ampliar las de los barrios periféricos, más poblados y más pobres. En segundo lugar, alumbrar el Paseo de los Mártires (hoy Explanada), por ser el lugar más concurrido y susceptible de promocionar el turismo. En tercer lugar, reducir las horas de alumbrado. Y, por último, satisfacer las deudas a la fábrica de gas. Por lo que se refería al proveedor del alumbrado por petróleo, al que se le adeudaban 29.700 reales, también se le debía de pagar la deuda. El Informe sugeria, asimismo, el aumento del número de vigilantes nocturnos. El Informe de la Comisión de Alumbrado en AMA. Alumbrado. Año 1872. Carpeta núm. 5.

46 A mediados de 1872 la Compañía no podía suministrar gas si el Ayuntamiento no anticipaba la cantidad precisa para la compra de carbón. Decía el director de la factoría que «confiando en ella (la cantidad adelantada), compraré el carbón necesario para el mes entrante, que asciende a 9.000 reales, cantidad que necesito mensualmente para atender a dicho alumbrado». AMA. Alumbrado. Año 1872. Carpeta núm. 5.

La falta de fondos municipales repercutía, asimismo, en los proveedores de carbón Newscastle en esta ciudad. En 1873 el director de la fábrica le comunicaba al Ayuntamiento que al no haber anticipado fondos suficientes, no disponía de dinero para comprar carbón Newscastle y los importadores, Jaes Hermanos y Compañía, también con problemas financieros, se negaban a suministrar más mineral de esta calidad. Se trataba de un círculo vicioso que atrapaba a todos los agentes económicos. El responsable de la fábrica decía que no tendría más remedio que «dejar la población a oscuras [en pocos días] (...) en que habré concluido con el poco carbón que tengo existente». La comunicación de Jaes Hermanos y Compañía en AMA. Alumbrado. Año 1873. Carpeta núm. 8. La imposibilidad de ampliar el servicio de alumbrado por gas explica que en 1873 se reorientara el viejo proyecto de iluminar la Explanada mediante esta energía, hacia el más asequible del petróleo, subastándose la construcción de 50 farolas de reverbero.

${ }^{77}$ Se nombró administrador judicial al director de la misma, José Guillem, que se seguiría quejando por los mismos motivos.

${ }^{48}$ En la carta de 31 de octubre de 1877 la Sociedad comunicaba que había nombrado un Inspector de servicios internos y externos, con la finalidad de mejorar el suministro. AMA. Alumbrado. Año 1877. Carpeta núm. 11. 
400.000 reales y ésta lo acusaba de llevarle a la ruina, amenazando con cortar el suministro ${ }^{49}$. Por esta razón se desprendió de la fábrica en 1880. A la nueva concesionaria, la Compañía Madrileña, tampoco le faltarían los problemas financieros vinculados a los impagos del Ayuntamiento ${ }^{50}$. Por último, convendrá hacer algún comentario a los cuadros siguientes, en relación a las cifras de los gastos presupuestados y liquidados por este servicio público, entre 1859 y 1874, comparándolos con los de las etapas $1815-1836$ y $1837-1858$.

En el cuadro II, en primer lugar, se constata que la media de los gastos presupuestados entre 1859 y 1874 (138.687 reales) quintuplicó sobradamente a la correspondiente al Ayuntamiento absolutista (24.197 reales) y casi triplicó la de los inicios del liberalismo (49.401 reales). Este hecho demuestra la voluntad política en la provisión de este servicio público. Ahora bien, y en segundo lugar, la media de los gastos realizados de 1859-1874, aun siendo superior a las anteriores etapas, reduce la diferencia. Así, la media de 73.919 reales casi triplicó la del Ayuntamiento absolutista (24.197 reales) y duplicó con creces la del subperíodo 1837-1858 (49.401 reales). Lo que demuestra que los proyectos políticos quedaban limitados por la efectiva capacidad financiera. En tercer lugar, siguió incrementándose la participación porcentual realizada en la partida del alumbrado público, dentro del capítulo de Policía Urbana, hasta alcanzar los 58 puntos, registrándose, asimismo, un aumento similar en relación a las etapas anteriores. Casi dos terceras partes del capítulo citado iba destinado a la partida reseñada. En cuarto lugar, el peso de los gastos de alumbrado, no obstante,

49 Carta de 4 de julio de 1879. AMA. Alumbrado. Año 1879. Carpeta núm. 12.

50 Aunque queda fuera del período que se ha fijado este trabajo, los problemas de esta empresa con la Corporación local confirman lo ya visto con anterioridad. El Ayuntamiento siguió pagando irregularmente. El 1 de julio de 1899 se firmó una nueva Escritura pública entre ambos organismos por la cual la Corporación reconoció una deuda de 323.276 pesetas. De nuevo el 9 de octubre de 1908, con una deuda reconocida de 1.046.159 pesetas, y el 31 de diciembre de 1909 , asumida la crecida deuda de 1.124 .201 pesetas, se otorgan nuevas Escrituras. Por la primera de ellas, el Ayuntamiento afecta al pago de la deuda y los gastos corrientes el rendimiento de los Consumos, que fue insuficiente. En 1911, al abolirse los Consumos, la Corporación ofrece como garantía el producto de los puestos públicos, pero limitando la cantidad debida a tan sólo 70.000 pesetas. La protesta de la concesionaria, que amenaza con retirar el fluido, es contestada por el Ayuntamiento, en 1912, con una unilateral e ilegal rescisión del contrato y el anuncio de sacar a pública subasta el servicio del alumbrado entre las empresas de electricidad. El recurso interpuesto por la Compañía ante el Gobernador obligó al Ayuntamiento a indemnizarla, el 2 de abril de 1913. AMA. Alumbrado. Año 1880. Carpeta núm. 13. ADPA. Contabilidad provincial. Años 1912-1913. Legajo 543. Recurso de la Compañía Madrileña de Alumbrado y Calefacción por Gas contra el Ayuntamiento de Alicante. 


\section{CUADRO II}

Gastos de alumbrado público por aceite, petróleo y gas de la ciudad de Alicante, en reales constantes, 1859-1874

\begin{tabular}{|c|c|c|c|c|c|}
\hline \multirow{2}{*}{ Años } & \multicolumn{2}{|c|}{ Gastos alumbrado } & \multirow{2}{*}{ Resultas } & \multirow{2}{*}{$\begin{array}{c}\text { Gastos } \\
\text { realizados } \\
\text { en Policía } \\
\text { Urbana }\end{array}$} & \multirow{2}{*}{$\begin{array}{c}\text { Gastos } \\
\text { totales } \\
\text { liquidados }\end{array}$} \\
\hline & Presupuestado & Realizado & & & \\
\hline 1859. & 93.308 & 97.850 & 4.543 & 142.164 & 820.742 \\
\hline 1860. & 100.711 & 101.802 & 1.092 & 149.717 & 1.200 .381 \\
\hline $1861 \ldots \ldots$ & 125.856 & 104.985 & 20.871 & 161.568 & 1.428 .669 \\
\hline $1862 \ldots \ldots$ & 194.868 & 128.667 & 66.200 & 226.955 & 1.350 .767 \\
\hline $1863-1864 \ldots$ & 117.333 & 53.942 & 63.390 & 105.780 & 893.101 \\
\hline $1864-1865 \ldots$ & 136.978 & 88.662 & 48.316 & 148.264 & 847.510 \\
\hline $1865-1866 \ldots \ldots \ldots \ldots$ & 112.794 & 100.251 & 12.543 & 155.853 & 855.295 \\
\hline $1866-1867 \ldots \ldots \ldots$ & 143.548 & 57.468 & 86.080 & 123.751 & 934.268 \\
\hline $1867-1868 \ldots \ldots \ldots \ldots$ & 163.097 & 108.450 & 54.647 & 160.292 & 1.219 .506 \\
\hline $1868-1869 \ldots \ldots \ldots$ & 141.419 & 72.589 & 68.831 & 134.521 & 827.860 \\
\hline $1869-1870 \ldots \ldots \ldots$ & 133.366 & 6.227 & 127.139 & 55.258 & 484.078 \\
\hline $1870-1871 \ldots \ldots \ldots$ & 164.640 & 249 & 164.391 & 78.084 & 852.299 \\
\hline $1871-1872 \ldots$ & 158.423 & 1.193 & 157.230 & 6.887 & 593.667 \\
\hline $1872-1873 \ldots$ & 160.241 & 75.734 & 84.507 & 124.764 & 886.837 \\
\hline $1873-1874 \ldots$ & 133.728 & 110.714 & 23.014 & 127.765 & 1.063 .965 \\
\hline Total & 2.080 .308 & 1.108 .783 & 982.794 & 1.901 .622 & 14.258 .946 \\
\hline Medias & 138.687 & 73.919 & 65.520 & 126.775 & 950.596 \\
\hline
\end{tabular}

Porcentaje sobre Policía Urbana . 58

Porcentaje sobre gastos totales.... 8

Porcentaje de lo realizado sobre lo presupuesta-

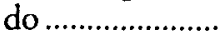

Deflactor utilizado: Sardá.

FUENTE: Elaboración a partir de la Contabilidad y Presupuestos de AMA y ADPA.

disminuyó en el total de gastos realizados ( 8 por 100 contra el 10 y 11 por 100 de las etapas anteriores), debido al incremento de otros gastos y al hecho de su no devengo, quedando así desplazado a un cuarto lugar, después de los gastos del Ayuntamiento (14 por 100), de las provisiones 
para el capítulo de las cargas (deudas) (12 por 100), del capítulo de Instrucción pública $(9$ por 100) y de las inversiones en obras públicas $(9$ por 100) ${ }^{51}$. Por último, la postergación de los pagos a ejercicios económicos posteriores nos lleva a observar el crecimiento sostenido, con alguna excepción, de las resultas por concepto de alumbrado, explicable por el hecho de que este Ayuntamiento sólo gastó la mitad (53 por 100) de las cantidades presupuestadas, con lo que se fueron aplazando los pagos y se acumularon las deudas. En lo que respecta al servicio per capita, mejoró claramente en relación al período liberal anterior: se pasó de 80 habitantes por luz a 57 habitantes por luz.

\section{CUADRO III}

Evolución de los gastos satisfechos por alumbrado de aceite, petróleo y gas en la ciudad de Alicante, en reales constantes, 1859-1874

\begin{tabular}{|c|c|c|c|}
\hline Años & Aceite y petróleo & Gas & Total \\
\hline 1859 & 82.637 & 0 & 82.637 \\
\hline 1860 & 85.029 & 0 & 85.029 \\
\hline 1861 & 50.650 & 30.088 & 80.738 \\
\hline 1862 & 43.816 & 79.121 & 122.936 \\
\hline $1863-1864 \ldots \ldots \ldots \ldots \ldots \ldots \ldots$ & 25.507 & 28.435 & 53.942 \\
\hline $1864-1865 \ldots \ldots \ldots \ldots \ldots \ldots \ldots \ldots$ & 28.450 & 60.212 & 88.662 \\
\hline $1865-1866 \ldots \ldots \ldots \ldots$ & 30.695 & 69.557 & 100.251 \\
\hline $1866-1867 \ldots \ldots \ldots$ & 37.466 & 18.594 & 56.059 \\
\hline $1867-1868 \ldots \ldots \ldots$ & 24.676 & 83.774 & 108.450 \\
\hline $1868-1869 \ldots \ldots \ldots \ldots \ldots \ldots \ldots$ & 13.233 & 59.356 & 72.589 \\
\hline $1869-1870 \ldots \ldots \ldots \ldots \ldots$ & 0 & 6.227 & 6.227 \\
\hline $1870-1871 \ldots \ldots \ldots \ldots \ldots$ & 0 & 249 & 249 \\
\hline $1871-1872 \ldots \ldots \ldots$ & 0 & 1.193 & 1.193 \\
\hline $1872-1873 \ldots \ldots$ & 0 & 75.734 & 75.734 \\
\hline $1873-1874 \ldots \ldots \ldots \ldots \ldots \ldots \ldots$ & 0 & 110.714 & 110.714 \\
\hline Total & 422.157 & 623.252 & 1.045 .409 \\
\hline $\begin{array}{l}\text { Porcentaje sobre gastos } \\
\text { totales }\end{array}$ & 40 & 60 & \\
\hline
\end{tabular}

Deflactor utilizado: Sardá.

FuENTE: Elaboración a partir de la Contabilidad y Presupuestos de AMA y ADPA.

51 Véase Salort (1997). 
En el cuadro III se observa el simultáneo proceso de crecimiento de los gastos realizados en alumbrado por gas, más de la mitad de los gastos (60 por 100), y la disminución de las magnitudes vinculadas a los sistemas por aceite y petróleo, menos de la mitad de los gastos totales de este servicio (el 40 por 100). Convendrá advertir que el alumbrado por gas empezó a generar gastos desde 1861 y que la ausencia de gastos por aceite y petróleo entre los ejercicios de $1869-70$ y $1873-74$ no se debe a que se suprimiera este servicio, sino a su absoluta falta de devengo.

Finalmente, el cuadro IV muestra la desviación entre las cantidades asignadas y las efectivamente realizadas para el suministro del alumbrado a gas. Hecho que se explica por las dificultades financieras del Ayuntamiento que, sin duda, tuvieron su inevitable repercusión en las compañías

\section{CUADRO IV}

Desviación entre lo presupuestado y lo realizado en gastos de alumbrado por gas en la ciudad de Alicante, en reales constantes, 1859-1874

\begin{tabular}{|c|c|c|c|}
\hline Años & Presupuestado & Liquidado & Deudas \\
\hline 1859 & 0 & 0 & 0 \\
\hline 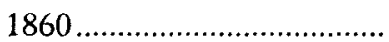 & 0 & 0 & 0 \\
\hline 1861 & 41.226 & 30.088 & 11.138 \\
\hline ……........ & 135.427 & 79.121 & 56.306 \\
\hline $1863-1864 \ldots \ldots \ldots$ & 85.024 & 28.435 & 56.588 \\
\hline $1864-1865 \ldots \ldots \ldots \ldots \ldots \ldots \ldots \ldots$ & 104.034 & 60.212 & 43.822 \\
\hline $1865-1866 \ldots \ldots \ldots \ldots \ldots \ldots \ldots$ & 78.088 & 69.557 & 8.532 \\
\hline $1866-1867 \ldots \ldots \ldots \ldots \ldots \ldots$ & 104.361 & 18.594 & 85.767 \\
\hline $1867-1868 \ldots \ldots \ldots \ldots \ldots \ldots \ldots \ldots \ldots \ldots \ldots \ldots$ & 115.127 & 83.774 & 31.353 \\
\hline $1868-1869 \ldots \ldots \ldots \ldots$ & 121.217 & 59.356 & 61.861 \\
\hline 1869-1870 & 115.136 & 6.227 & 108.909 \\
\hline 1870-1871 & 140.547 & 249 & 140.298 \\
\hline $1871-1872 \ldots \ldots \ldots \ldots \ldots \ldots \ldots \ldots$ & 132.019 & 1.193 & 130.826 \\
\hline $1872-1873 \ldots \ldots \ldots \ldots \ldots \ldots$ & 133.186 & 75.734 & 57.452 \\
\hline $1873-1874 \ldots \ldots$ & 113.998 & 110.714 & 3.284 \\
\hline Total.. & 1.419 .388 & 623.252 & 796.136 \\
\hline Media.. & 109.184 & 44.942 & 61.241 \\
\hline
\end{tabular}

Porcentaje de lo liquidado

sobre lo presupuestado.... 44

Deflactor utilizado: Sardá.

FUENTt: Elaboración a partir de la Contabilidad y Presupuestos de AMA y ADPA. 
concesionarias. Del monto total de las cantidades presupuestadas (1.419.388 reales), sólo se satisfizo el 44 por 100 (623.252 reales). El 56 por 100 restante ( 796.136 reales) pasó al capítulo de «Cargas» o deudas, como un agregado más, que se fueron haciendo efectivas ínfima e irregularmente, a tenor de las quejas de las compañías arrendatarias. El cálculo de las deudas canceladas por este concepto por su devengo ha sido imposible de realizar, porque en los datos contables de las «Cargas» de este Ayuntamiento, como ya se ha dicho, aparecen agregadas diversas cantidades por distintos conceptos, correspondientes a créditos en contra de la Corporación.

\section{CONCLUSIONES}

De todo lo expuesto se pueden destacar las siguientes conclusiones. En primer lugar, desde el punto de vista del demandante, se puede afirmar que la ciudad dispuso de un servicio público bajo la luz de la precariedad presupuestaria y la situación deficitaria estructural. Y este hecho se explica, fundamentalmente, por la subordinación de la Hacienda local a las necesidades de la Hacienda central - y centralista-, como creo haber justificado en $\mathrm{mi}$ tesis doctoral ${ }^{52}$. Una insuficiencia financiera vinculada a la competencia de las dos instituciones por las mismas materias fiscales; al control de la primera respecto de la segunda en la autorización de los gravámenes; a las transferencias municipales al Tesoro, cuya no satisfacción completa generaba deudas y gastos ${ }^{53}$; a la privación de la función recaudadora local; a la descapitalización derivada del proceso desamortizador; y a la pérdida de ingresos por la abolición de casi todos los monopolios, a raíz de la introducción de la economía de mercado. La penuria en los ingresos se pone de manifiesto en la disparidad entre la esperanza política y la efectiva capacidad recaudatoria, palmariamente constatada en la desviación entre los ingresos presupuestados y los recaudados, efecto que ineluctablemente se trasladaba a los gastos ${ }^{54}$. A mayor abundamiento, en cuan-

${ }^{2}$ Véase Salort (1997).

${ }^{53}$ Durante todo el siglo Xrx, y antes, la Hacienda central practicó una punción permanente y constante respecto de los bienes de propios y de los arbitrios de esta Hacienda municipal en concepto de contribuciones, que rondaba el 20 por 100 de sus recursos. Y en los años treinta y cuarenta, las transferencias alcanzaron el 40 por 100 de sus ingresos. Para este asunto, véase Salort (1997).

${ }^{54}$ El grado de desviación entre los ingresos previstos y los recaudados alcanzó un promedio de más de 40 puntos entre 1846 y 1874 . Las previsiones de gastos fueron inferiores 
to a estos últimos, se aplicó la filosofía liberal de confiar a las Haciendas locales muchas responsabilidades, sin incrementar, eso sí, su capacidad financiera ${ }^{55}$. El recorte del gasto estaba servido, y aun así, no se podía evitar el creciente endeudamiento. Inevitablemente, el Ayuntamiento no podía sino ofrecer unos limitados y deficientes servicios. Este extremo se evidencia en la provisión del alumbrado público de esta ciudad, de forma doble, tanto por los datos empíricos, como por los testimonios documentales. Es significativo que los gastos por transferencias y deudas, fundamentalmente a la Hacienda central, siempre alcanzaron una proporción superior a la de la partida del alumbrado.

$\mathrm{La}$ insuficiencia financiera y el endeudamiento municipal nos lleva a la segunda consideración, concerniente a la perspectiva de los oferentes del servicio de alumbrado público. Esta provisión estuvo en régimen de administración directa durante cortos períodos de tiempo. Pero siempre prevaleció la cesión a particulares. En este sentido la Administración favoreció la participación de la iniciativa privada en este ramo. Antes de la llegada del gas, el Ayuntamiento prefería asegurarse un gasto fijo y evitar el alza del precio del aceite y petróleo; y después, se veía incapaz de hacer frente a los grandes costes de inversión y a la complejidad en el proceso de fabricación y distribución del gas. Ahora bien, la repercusión de la morosidad municipal en los arrendadores individuales del servicio, en las compañías concesionarias y en los importadores y proveedores de carbón, produjo la ruina de algunos suministradores del alumbrado por aceite y petróleo y creó situaciones límite en las empresas proveedoras del gas, al descapitalizarlas. La experiencia constatada en este trabajo viene a reforzar las tesis de Sudrià (1983) y Nadal (1992) de que las frustradas perspectivas inversoras de las empresas del gas y, por tanto, el desarrollo de esta industria, estuvieron vinculadas, fundamentalmente, a la demanda ${ }^{56}$. Incluida la demanda institucional. Es significativo el hecho de que ninguna de las

en 26 puntos a lo efectivamente realizado durante la etapa citada. Para la subordinación de las Haciendas locales a las necesidades de la Hacienda central, véase Salort (1996 y 1997).

"Y es que, como atinadamente han expuesto Francisco Comín y Carmen García, «en el siglo XIX, la Administración local no pasó de ser un mero apéndice de la Administración central, pues los liberales únicamente cedieron a los entes locales aquellas funciones que no podían ser desempeñadas por el Estado». Véase Comín y García (1995), p. 90. También para este asunto, Comín (1996), pp. 202-203.

${ }^{56}$ En opinión de Sudrià (1983), la singladura de las empresas del gas en España estuvo limitada, entre otros extremos, por los bajos niveles de consumo particular, habida cuenta de los bajos niveles de renta; porque los precios al consumo no compensaban suficientemente los costes medios; por la tendencia a la baja en los precios de venta del gas y por el incremento 
concesionarias de gas que operaron en esta ciudad durante este tramo cronológico agotaron los plazos fijados, aunque intentaron ampliarlos. Los nuevos tenedores, a pesar de aumentar el precio del suministro, disminuir la potencia, estar exentas de los recargos municipales o no satisfacer el canon de usufructo, de endurecer las condiciones de suministro a particulares y de ejercer prácticas monopolistas indebidas, no lograron mantenerse. Las razones que podrían explicar su entrada en el negocio, a pesar de los incumplimientos municipales, habría que buscarlas en la confianza en el incremento del consumo privado y/o en la obtención de beneficios con el traspaso de la concesión. Todo ello podría matizar o ratificar la hipótesis de Antolin (1991), en relación a la rentabilidad de las compañías de gas en España ${ }^{57}$. Las insistentes quejas, desesperadas declaraciones y numerosas amenazas de las empresas del gas, por la morosidad e insolvencia de este Ayuntamiento y por la estrechez del mercado particular, reiteradamente documentadas en este trabajo, son esclarecedoras al respecto.

La tercera consideración es la constatación de que, a pesar de las dificultades de diversa índole, la población de Alicante vio mejorada sus condiciones de vida con el perfeccionamiento de esta prestación pública, desde finales del siglo XVIU hasta el último tercio del siglo XIX. La revolución liberal, la economía de mercado y el incremento demográfico supusieron una solución de continuidad tanto desde el punto de vista de la ampliación de este servicio, como desde el de la innovación tecnológico-energética, con la sustitución paulatina del alumbrado de aceite por el del petróleo y el gas. Una mayor y más racional asignación presupuestaria de los recursos municipales contribuyó a dichos cambios. A finales del siglo XIX y principios del xx se podría atisbar ya la transición entre la Hacienda municipal estric-

de los precios vinculado a la baja cotización de la peseta, lo que encarecía el precio de hulla británica y los fletes. Por su parte, Nadal, después de constatar el hecho de que una buena parte del carbón importado durante los últimos veinte años del siglo xIX fue consumido por las fábricas de gas y poner de relieve el impacto de su aplicación en el alumbrado, resalta la prioridad del factor demanda sobre el de oferta, como condicionante en el desarrollo de la industria gasista en España. A este propósito manifiesta que «hay que insistir sobre lo que ya se ha dicho: la expresión de la industria gasista en España, durante la segunda mitad del siglo XIX, no depende de las condiciones de oferta sino del nivel de demanda, acaba siendo, en definitiva, una cuestión de ventas». Véase Nadal (1992), p. 105.

57 F. Aniolín sostiene que «poco es lo que sabemos sobre la rentabilidad de las compañías de gas en España, pero se puede avanzar que los resultados debieron ser positivos para todas aquellas que se mantuvieron en activo durante períodos prolongados». Y añade que quizás el objetivo de vender la concesión una vez instaladas las fábricas era, precisamente, el previsto por los grupos financieros extranjeros. Véase Antolín (1983), pp. 310-311. 
tamente liberal a otra de incipiente bienestar. Ello permite enlazar la cuestión de la provisión del servicio del alumbrado público en esta ciudad, con las teorías del monopolio natural y del Estado de bienestar, apuntadas por Núñez (1996) ${ }^{58}$.

Finalmente, parece razonable atribuir parte de la responsabilidad de las vicisitudes por las que pasó esta provisión municipal, y todas las demás, y del atraso industrializador en la actividad gasística, en la inadecuada intervención de un Estado permanentemente agobiado por el déficit y la deuda, cuyos efectos perversos, directos e indirectos, trasladaba a las instituciones municipales y sobre los agentes económicos, es decir, los proveedores de aceite, petróleo y gas. A este propósito es esclarecedor el hecho de que si este Ayuntamiento hubiera podido dejar de transferir a la Hacienda central las contribuciones sobre Propios y Arbitrios (1.083.567 reales entre 1800 y 1845 y 1.300 .000 reales entre 1846 y 1874), habría prestado un mejor servicio de alumbrado y evitado la descapitalización de los individuos y las empresas concesionarias del suministro.

\section{BIBLIOGRAFÍA}

ANToLín, F. (1991): «Las empresas de servicios públicos municipales», en F. Comín y P. Martin Aceña (eds.), Historia de la empresa pública en España, Madrid, Espasa Calpe.

Broder, A. (1981): «Le rôle des intérets économiques étrangers dans le croissance de l'Espagne au Xxx siècle», Thèse pour l'obtention du doctorat d'Etat, Paris.

Comín, F. (1996): Historia de la Hacienda pública, II, España (1808-1995), Barcelona, Crítica.

Comin, F., y Garcia, C. (1995): «Reforma liberal, centralismo y Haciendas municipales en el siglo XIX», en Hacienda Pública Española, núm. 133.

Costa Campi, M. ${ }^{a}$ T. (1981): «Iniciativas empresariales y capitales extranjeros en el Sector Servicios de la Economía española, durante la segunda mitad del siglo XIX», en Investigaciones Económicas, núm. 14.

NADAL, J. (1992): Moler, tejer y fundir. Estudios de historia indristrial, Barcelona, Ariel.

NúNez Romero-Balmas, G. (1996a): «Servicios urbanos colectivo en España durante la segunda industrialización: entre la empresa privada y la gestión pública»,

${ }^{58} \mathrm{G}$. Núñez apunta que «el contexto histórico en que (...) tuvieron origen la teoría del monopolio natural y la teoría del Estado de bienestar, estuvo estrechamente asociado al fenómeno (...) [de los] monopolios locales [y del] socialismo municipal. Del mismo modo que entonces los problemas de la vida urbana realimentaron el desarrollo de la teoría, el estudio detenido de aquellas actividades debe contribuir a su reinterpretación y renovación». Véase Núñez Romero-Balmas (1996b), p. 12. 
en F. Comín y P. Martín Aceña (eds.), La empresa en la bistoria de España, Madrid, Civitas.

- (1996b): «Infraestructuras y servicios públicos urbanos: hipótesis de trabajo y notas bibliográficas», en Ciudad y Territorio, núm. 108.

Ramos, A. (1984): Evolución urbana de Alicante, Alacant, Institut d'Estudis «Juan Gil Albert».

SALORT, S. (1996): «Las Haciendas locales entre el Antiguo Régimen y el reformismo burgués. La Hacienda municipal de Alacant (1800-1923)», en Hacienda Pública Española.

- (1997): La Hacienda local en la España contemporánea. La Hacienda municipal de Alacant (1800-1923), Alacant, Institut d'Estudis «Juan Gil Albert».

SuDRIÀ, C. (1983): «Notas sobre la implantación y el desarrollo de la industria del gas en España, 1840-1901», en Revista de Historia Económica, núm. 2.

Tortella, G. (1982): Los orígenes del capitalismo en España, Madrid, Tecnos.

- (1994): El desarrollo de la España contemporánea. Historia económica de los siglos XIX y XX, Madrid, Alianza.

\section{FUENTES}

NO IMPRESAS

Arxiu Municipal d'Alacant (AMA).

Arxiu de la Diputació Provincial d'Alacant (ADPA).

IMPRESAS

Boletin Oficial de la Provincia de Alicante (BOPA). 